\title{
Positional Accuracy Assessment for Effective Shoreline Change Analyses*
}

\author{
C. B. Boye, K. Appeaning Addo and E. A. Williams
}

Boye, C. B., Appeaning Addo, K. and Williams, E. A. (2016), "Positional Accuracy Assessment for Effective Shoreline Change Analyses", Ghana Mining Journal, Vol. 16, No. 1, pp. 1 - 7.

\begin{abstract}
The usefulness of any geographic data depends on its fitness for a particular purpose. The critical measure of that fitness is referred to as data quality. Data quality may be expressed in terms of several indicators such as attributes, temporal or positional accuracies. In this research, positional accuracy assessment was carried out on two datasets using Root Mean Square Error (RMSE) technique. Coordinates of nineteen ground controls points were measured in the field using Differential Global Positioning System technique which served as a reference base. The coordinates of these points were compared with their corresponding positions extracted from the two datasets, Town Sheet (1: 2500) and orthophoto (1: 5000). The Town Sheet was scanned, rescaled (1:5000) and georeferenced in Ghana Meter Grid coordinate system to conform to the orthophoto. The digitised Town Sheet and the reference base were superimposed with the orthophoto serving as backdrop in GIS environment. Positional error of $1.23 \mathrm{~m}$ was obtained for points extracted from the Town Sheet, while an error of $2.79 \mathrm{~m}$ was registered for points from the orthophoto. Shoreline features extracted from these two datasets and appended for shoreline change analysis recorded a total positional error of $3.98 \mathrm{~m}$. The study has shown that the original scale (large) of the Town Sheet may have contributed significantly to the quality of data extracted. In the orthophoto, though geometrically rectified, the scale representation of a unit measure on the photo explains the uncertainties in the dataset. The integrated dataset obviously bore the cumulative effect of the input datasets. It is concluded that for the purpose of shoreline change analysis, such as shoreline change trends, large scale data sources should be used where possible for accurate decision-making. It is recommended that the positional accuracy of any spatial data be ascertained before using it to support decision.
\end{abstract}

Keywords: Positional Accuracy, Shoreline Change, Differential GPS, Root Mean Squared Error, Orthophoto

\section{Introduction}

Spatio-temporal data deal with geographic features which change geometry over a period of time (Erwig et al., 1999). Strictly speaking, all physical features on the surface of the earth (e.g. rivers, forest etc.) fall within this category due to plate tectonic movements. In practice, however, such changes in geometry over a time period are assumed to be negligible compared to those recorded in some features such as shoreline which changes its location over relatively shorter period of time due to factors like tides, storm or climate change.

The shoreline, which is the interface between land and water (Boak and Turner, 2005), is swayed by several factors but it serves as a good indicator to coastal erosion (Srivastava et al., 2005). Erosion of the coast is a worldwide challenge attributed mainly to sea-level rise, change in storm climate (Nicholls et al., 2010; Zhang, 2004) and human interference with coastal processes. Since most of these causative factors are dependent on physical processes and human induced climate change, averting the trend is often difficult. An alternate solution could be achieved through numerical modelling, which enables future shoreline change trend to be predicted. The prediction of shoreline change trend is crucial for coastal management and infrastructural development.

Positional accuracy assessment is an important method of evaluating the quality of spatial dataset (Girres and Touga, 2010). It determines how closely the positions of discrete objects or features are compared to their actual locations on ground (Congalton and Green, 2008). Effective resource mapping requires accurate maps or at least maps of known accuracy. Earlier studies attest to this fact. Potere (2008), for instance, tested for positional accuracy of Landsat Geocover dataset using 436 control points located in 109 cities; Becek and Ibrahim (2011) estimated the positional accuracy of runways compiled from multiples sources using 2045 controls. Other useful studies have been carried out in this respect in other parts of the world (Yousefzadeh and Mojaradi, 2012; Naji et al., 2013; Pujotomo and Sudibyakto, 2009). Although the positional accuracies of individual datasets are assessed, the total uncertainties of the integrated data are rarely determined.

This research used Root Mean Square Error (RMSE) technique to assess the horizontal accuracy associated with individual input datasets as well as determine the uncertainties in the integrated dataset. 


\section{Resources and Methods Used}

Sekondi-Takoradi, the administrative capital of the Western Region of Ghana, is the study area (Fig. 1). It lies between latitude $01^{\circ} 46^{\prime} \mathrm{W}$ and longitude $4^{\circ} 55^{\prime} \mathrm{N}$ and has elevation range not exceeding 100 $\mathrm{m}$ above mean sea level. It has a land area of 385 $\mathrm{km}^{2}$ and is strategically located in the SouthWestern part of Ghana, about 242 kilometers to the West of Accra, the capital city. It is also approximately 280 kilometers from the La Cote d'lvoire border in the West. It is surrounded by Mpoho-Wassa East District Assembly on the north, Gulf of Guinea on the south, Shama District Assembly on the East and Ahanta West District on the West (Anon., 2006).

Data used for the study comprises a Town Sheet of scale 1:2500 produced in 1992, a rectified aerial orthophoto of scale 1:5000 taken in 2005 obtained from the Survey and Mapping Division of the Lands Commission (Ghana), and GPS measurement of ground controls - adopting the differential GPS technique. The leap frog method was used in the traverse over the nineteen (19) ground controls points and the data was post processed using the Spectrum Survey Software. For the assessment of planimetric positional errors of each data, the coordinates of the controls, which were clearly visible in both the Town Sheet and the orthophoto were extracted and their corresponding coordinates compared with those of the GPS observation. Assuming negligible errors in the post processed GPS data (i.e. reference base data), the positional accuracy of each dataset was assessed by the RMSE technique. The technique allows comparison between coordinates of ground controls points extracted from maps, orthophoto etc., and those of their responding reference base data (Farah and Agarni, 2014; Anon., 1998; ParedesHarnandex et al., 2013). The RMSE of the X and Y coordinates of any point $\mathrm{P}$ as well as the RMSE of the position are given in Equations 1-3.

$$
\begin{aligned}
\operatorname{RMSE}_{\mathrm{x}}=\sqrt{\frac{\left(\mathrm{X}_{\text {datai }}-\mathrm{X}_{\text {ref datai }}\right)^{2}}{n}} & \text { Eqn 1 } \\
\operatorname{RMSE}_{\mathrm{Y}}=\sqrt{\frac{\left(\mathrm{Y}_{\text {datai }}-\mathrm{Y}_{\text {ref datai }}\right)^{2}}{n}} & \text { Eqn 2 } \\
\operatorname{RMSE}_{P}=\sqrt{\left(R M S E_{X}\right)^{2}+\left(R M S E_{Y}\right)^{2}} & \text { Eqn 3 }
\end{aligned}
$$

where data $i$ is the coordinates of the $i^{\text {th }}$ extracted point from the map or orthophoto and ref data $i$ is the coordinates of the responding $i^{\text {th }}$ coordinates of point measured from the field.

For effective data integration, the Town Sheet was scanned, rescaled to 1:5000 and georeferenced in Ghana Meter Grid (GMG) coordinate system to conform to that of the orthophoto. The digitized Town Sheet layer and the reference base point data layer were displayed together with the orthophoto serving as a backdrop in a GIS environment. The deviations of the coordinates were computed applying the RMSE Equations for the eastings, northings and the overall positional accuracy. By similar analysis, the positional errors inherent in the integrated data (such as shorelines) from these two data sources were also evaluated and analysed. The RMSE technique was used because it is simple to understand and also gives an indication of the data quality used therefore a measure of goodness of fit.

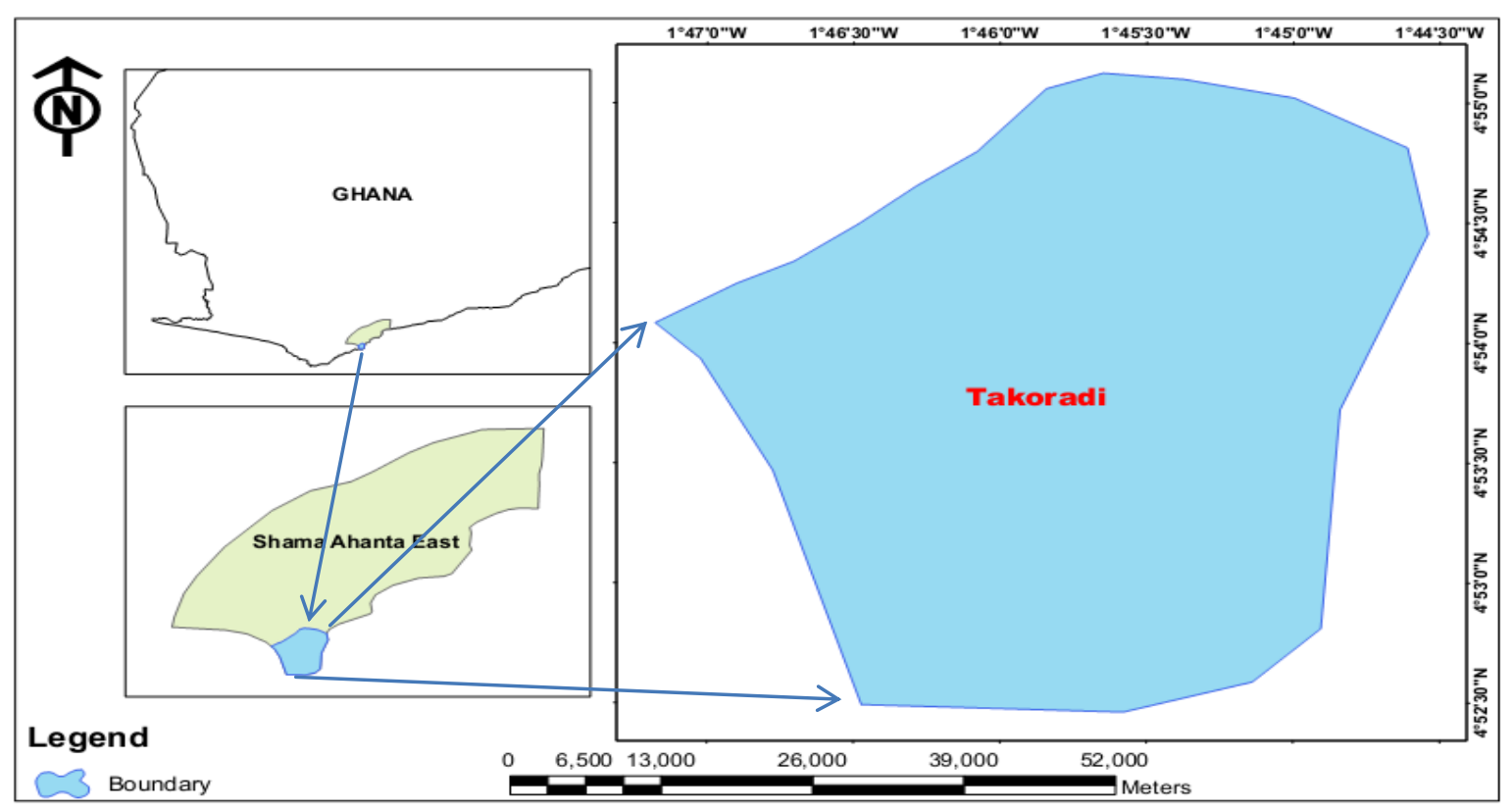

Fig. 1 Map of the Study Area 


\section{Results and Discussion}

The shifts in coordinates of the extracted points from the Town Sheet as compared to that of the GCPs are presented in Table 1 and Fig. 2. The deviations in the Northings, Eastings and their positional errors computed at each site are also shown. With the exception of points 4 and 17, all the discrepancies range between 0 and $2 \mathrm{~m}$ in the Eastings, Northings and the positional errors, except for point 8 which deviated in excess of $3 \mathrm{~m}$. Minimal deviations were recorded from GCP 9 through to 14 and points 18 and 19. Considering points 4,8 and 17 as outliers, a RMSE of $1.23 \mathrm{~m}$ is obtained for the Town sheet. A comparison of the GPS coordinates and that of the orthophoto (see Table 2) showed relatively higher deviations; points 5 and 13 showing the most deviance (see Fig. 3). A RMSE of $2.78 \mathrm{~m}$ was obtained by considering points 5 and 13 as outliers (deviations: $\delta>3 \times \sigma)$.

\subsection{Uncertainties in the Town Sheet}

From Fig. 2, the discrepancies of the coordinates of the controls extracted from the Town Sheet relative to the GPS data generally show a deviation less than $2 \mathrm{~m}$. This represents an error of $0.8 \mathrm{~mm}$ on Town Sheet at same scale. Both the northings and the eastings coordinates from the Town Sheet vary slightly from the reference coordinates in varying magnitudes giving an indication of the presence of random errors. It was observed that minimal deviations were recorded from GCP 9 through to 14. This observation supports the study assumption of negligible errors about the GPS reference base data used. The mean positional accuracy of $1.2 \mathrm{~m}$ in the dataset connotes high quality in the Town Sheet used.
The outcome of the overlay of the three datasets is shown in Fig. 4 and the errors in the integrated data were also evaluated. Excluding the outliers, an average RMSE of $3.98 \mathrm{~m}$ was realized in the integrated dataset. For instance, shoreline features extracted from these two dataset and appended for shoreline change analysis would record a total positional error of $3.98 \mathrm{~m}$. A scatter plot of the inherent errors and the integrated datasets errors are shown in Fig. 5 .

Reliance on spatial data to support decision-making is essential at all levels. However, the quality of the information derived is tied to the uncertainties inherent in the datasets employed. Although some degree of errors exist in most datasets at all scales, it is imperative that efforts be made to declare the uncertainties in datasets so that users may decide on their fitness for a given purpose or otherwise.

This makes the dataset useful for engineering applications as well as for spatio-temporal predictions. The achieved positional errors may be due to the following reasons:

(i) The Town Sheet was produced from aerial photographic sources with a touch of ground verification coupled with cartographic enhancement.

(iii) The data was free from excess pictorial information which is capable of causing mismatch of ground features.

(iii) The large scale of the source Town Sheet (1:2500) presented relatively higher details per unit measure of area, thus the accuracy obtained.

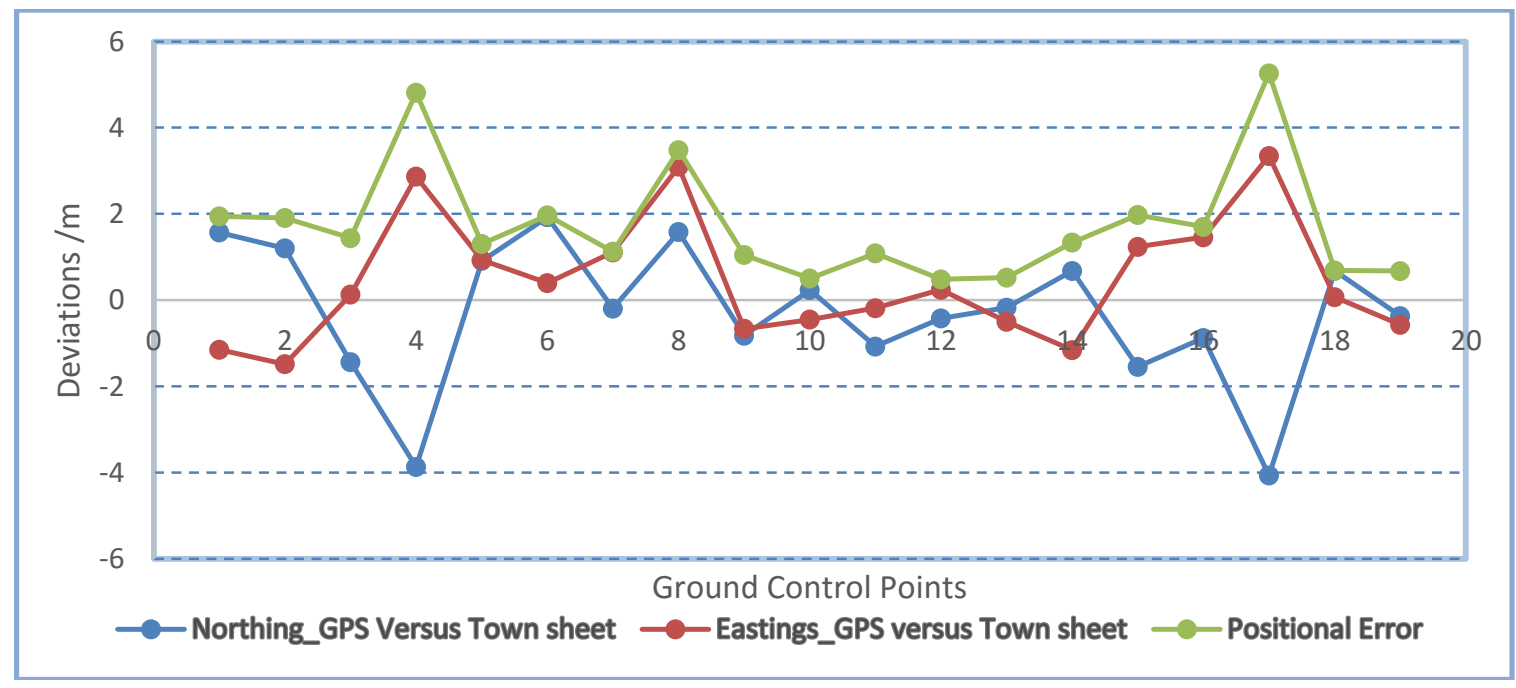

Fig. 2 Discrepancies between GPS Coordinates and Town sheet Coordinates 
Table 1: Positional Accuracy Assessment for Points Extracted from Town Sheet

\begin{tabular}{|c|c|c|c|c|c|c|c|c|}
\hline \multirow[b]{2}{*}{ ID } & \multicolumn{2}{|c|}{ GPS Coordinates } & \multicolumn{2}{|c|}{ Town Sheet Coordinates } & \multicolumn{2}{|c|}{ Deviations } & \multicolumn{2}{|c|}{ Variances } \\
\hline & $(\mathrm{N}) / \mathrm{m}$ & $(\mathrm{E}) / \mathrm{m}$ & $\mathrm{E}_{\mathrm{T}}$ & $\mathrm{N}_{\mathrm{T}}$ & $\Delta \mathrm{N}_{\mathrm{T}} \mathrm{N}$ & $\Delta \mathrm{E}_{\mathrm{T}} \mathrm{E}$ & $\left(\Delta \mathrm{N}_{\mathrm{T}} \mathrm{N}\right)^{2}$ & $\left(\Delta \mathrm{E}_{\mathrm{T}} \mathrm{E}\right)^{2}$ \\
\hline 1 & 23679.814 & 191062.335 & 23678.240 & 191063.481 & 1.570 & -1.146 & 2.4649 & 1.3133 \\
\hline 2 & 23551.115 & 191126.037 & 23549.910 & 191127.517 & 1.205 & -1.480 & 1.4520 & 2.1904 \\
\hline 3 & 23648.106 & 191210.249 & 23649.540 & 191210.116 & -1.434 & 0.133 & 2.0564 & 0.0177 \\
\hline 4 & 23434.665 & 191320.981 & 23438.530 & 191318.112 & -3.866 & 2.869 & 14.9460 & 8.2312 \\
\hline 5 & 23597.887 & 190931.773 & 23596.970 & 190930.841 & 0.913 & 0.932 & 0.8336 & 0.8686 \\
\hline 6 & 23219.069 & 190743.241 & 23217.140 & 190742.842 & 1.934 & 0.399 & 3.7404 & 0.1592 \\
\hline 7 & 23662.627 & 190558.784 & 23662.820 & 190557.673 & -0.189 & 1.111 & 0.0357 & 1.2343 \\
\hline 8 & 23786.024 & 190914.283 & 23784.440 & 190911.183 & 1.582 & 3.100 & 2.5027 & 9.6100 \\
\hline 9 & 23615.619 & 190530.418 & 23616.440 & 190531.076 & -0.823 & -0.658 & 0.6773 & 0.4330 \\
\hline 10 & 23854.659 & 190556.227 & 23854.420 & 190556.673 & 0.238 & -0.446 & 0.0566 & 0.1989 \\
\hline 11 & 23571.347 & 190108.281 & 23572.420 & 190108.465 & -1.074 & -0.184 & 1.1535 & 0.0339 \\
\hline 12 & 23761.791 & 190129.255 & 23762.210 & 190129.011 & -0.422 & 0.244 & 0.1781 & 0.0595 \\
\hline 13 & 23806.329 & 190114.532 & 23806.500 & 190115.029 & -0.166 & -0.497 & 0.0276 & 0.2470 \\
\hline 14 & 23321.07 & 190028.599 & 23320.390 & 190029.754 & 0.678 & -1.155 & 0.4597 & 1.3340 \\
\hline 15 & 23874.667 & 190884.311 & 23876.210 & 190883.072 & -1.541 & 1.239 & 2.3747 & 1.5351 \\
\hline 16 & 23914.205 & 190515.711 & 23915.080 & 190514.251 & -0.876 & 1.460 & 0.7674 & 2.1316 \\
\hline 17 & 23981.299 & 190976.499 & 23985.360 & 190973.154 & -4.063 & 3.345 & 16.5080 & 11.1890 \\
\hline 18 & 23553.895 & 190759.318 & 23553.210 & 190759.245 & 0.690 & 0.073 & 0.4761 & 0.0053 \\
\hline 19 & 23161.723 & 190071.223 & 23162.090 & 190071.792 & -0.369 & -0.569 & 0.1362 & 0.3238 \\
\hline & & & & & & Sum & 50.8467 & 41.1159 \\
\hline & & & & & & RMSE & 1.68072 & 1.51136 \\
\hline
\end{tabular}

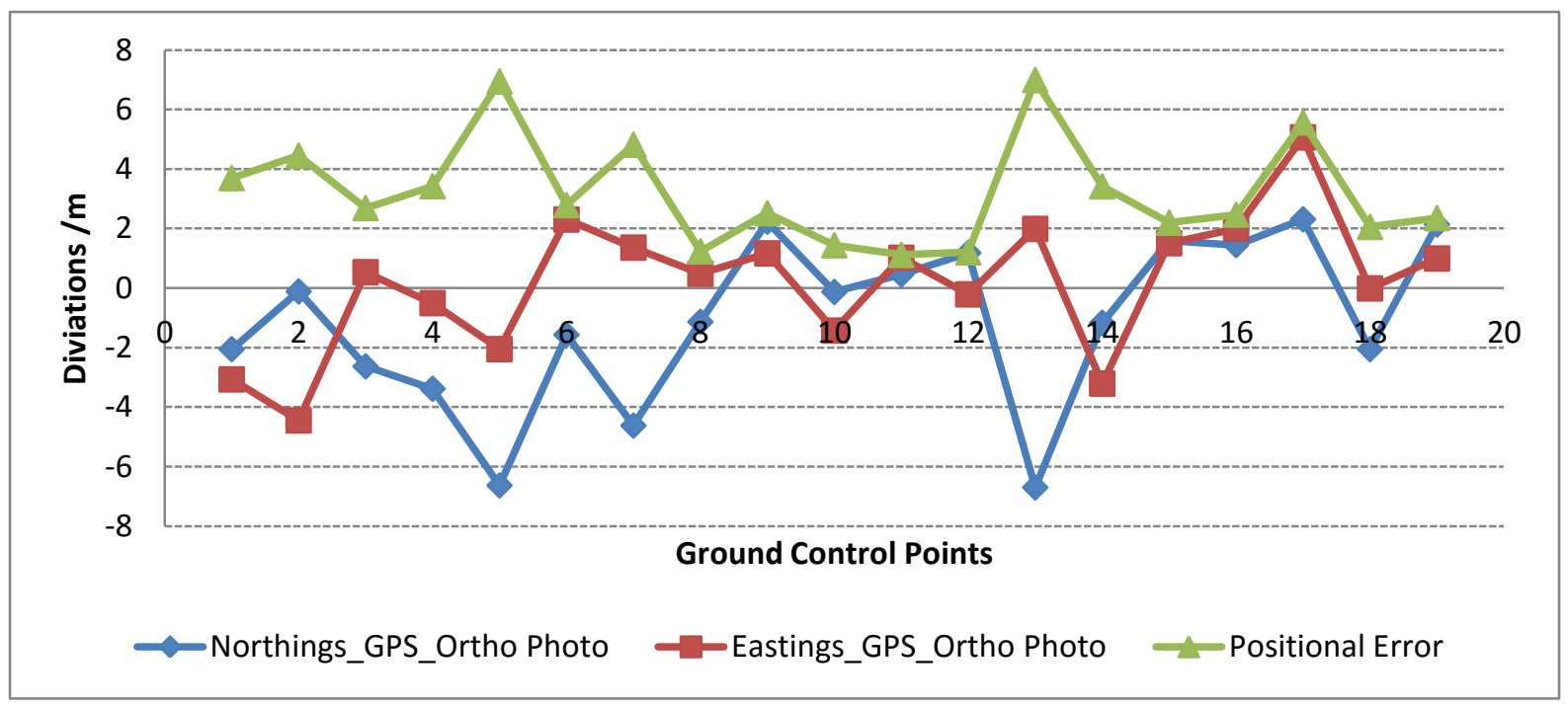

Fig. 3 Discrepancies between GPS Coordinates and Ortho Photograph 


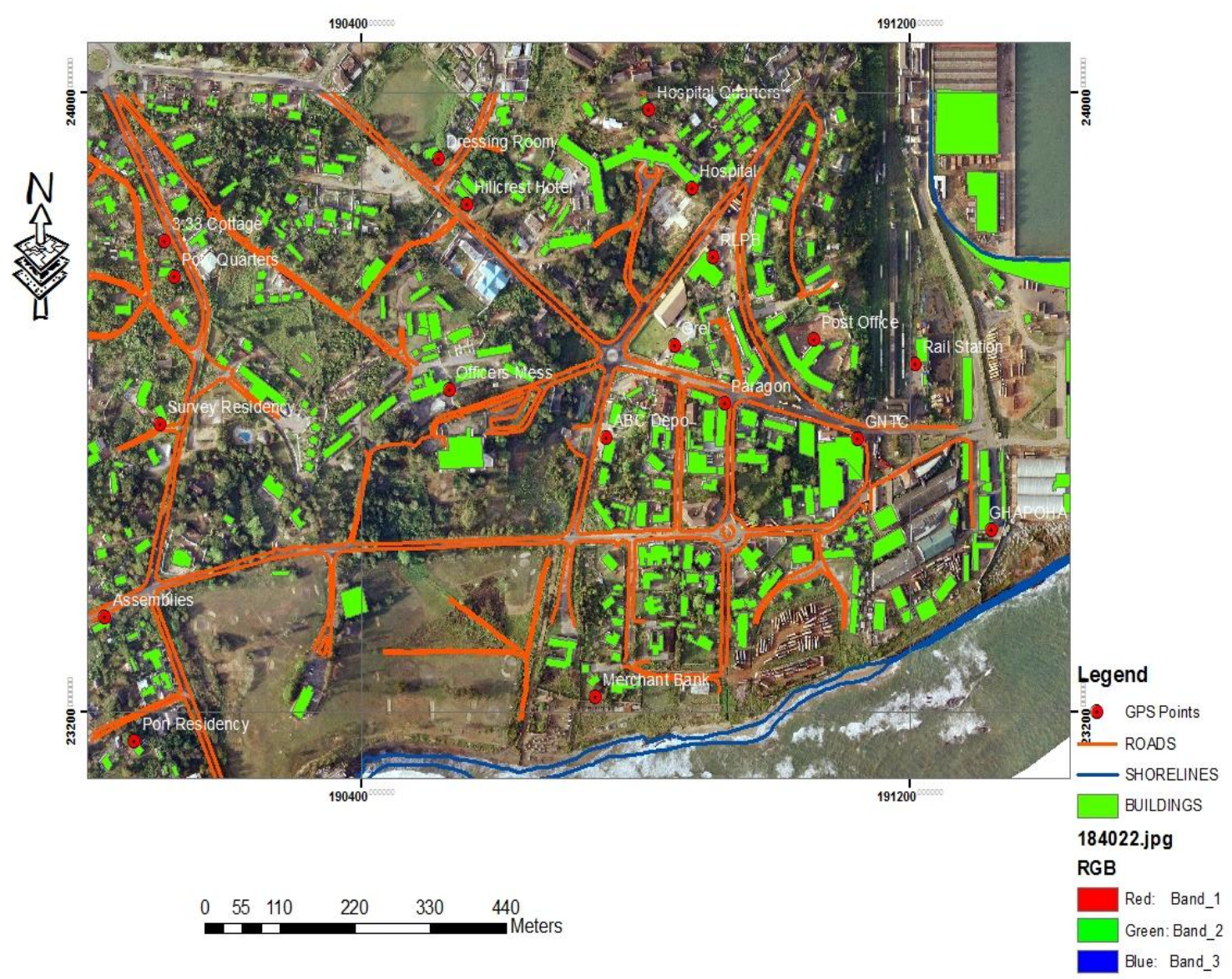

Fig. 4 The Integrated Map

Table 2: Positional Accuracy Assessment for Points Extracted from orthophoto

\begin{tabular}{|c|c|c|c|c|c|c|c|c|}
\hline \multirow[b]{2}{*}{ ID } & \multicolumn{2}{|c|}{ GPS Coordinates } & \multirow{2}{*}{$\begin{array}{l}\text { Orthophoto } \\
E_{\mathrm{O}} / \mathrm{m}\end{array}$} & \multirow{2}{*}{$\begin{array}{l}\text { Coordinates } \\
\mathrm{N}_{\mathrm{O}} / \mathrm{m}\end{array}$} & \multicolumn{2}{|c|}{ Deviations } & \multicolumn{2}{|c|}{ Variances } \\
\hline & $(\mathrm{N}) / \mathrm{m}$ & (E) $/ \mathrm{m}$ & & & $\Delta \mathrm{N}_{\mathrm{O}} \mathrm{N}$ & $\Delta \mathrm{E}_{\mathrm{O}} \mathrm{E}$ & $\left(\Delta \mathrm{N}_{\mathrm{O}} \mathrm{N}\right)^{2}$ & $\left(\Delta \mathrm{E}_{\mathrm{O}} \mathrm{E}\right)^{2}$ \\
\hline 1 & 23679.814 & 191062.335 & 23681.870 & 191065.405 & -2.054 & -3.070 & 4.2189 & 9.4249 \\
\hline 2 & 23551.115 & 191126.037 & 23551.230 & 191130.487 & -0.118 & -4.450 & 0.0139 & 19.8025 \\
\hline 3 & 23648.106 & 191210.249 & 23650.740 & 191209.717 & -2.636 & 0.532 & 6.9485 & 0.283024 \\
\hline 4 & 23434.665 & 191320.981 & 23438.050 & 191321.488 & -3.382 & -0.507 & 11.4379 & 0.2570 \\
\hline 5 & 23597.887 & 190931.773 & 23604.520 & 190933.826 & -6.637 & -2.053 & 44.0498 & 4.2148 \\
\hline 6 & 23219.069 & 190743.241 & 23220.640 & 190740.938 & -1.566 & 2.303 & 2.4524 & 5.3038 \\
\hline 7 & 23662.627 & 190558.784 & 23667.250 & 190557.426 & -4.621 & 1.358 & 21.3536 & 1.8442 \\
\hline 8 & 23786.024 & 190914.283 & 23787.160 & 190913.804 & -1.138 & 0.479 & 1.2950 & 0.2294 \\
\hline 9 & 23615.619 & 190530.418 & 23613.390 & 190529.254 & 2.227 & 1.164 & 4.9595 & 1.3549 \\
\hline 10 & 23854.659 & 190556.227 & 23854.790 & 190557.657 & -0.130 & -1.43 & 0.0169 & 2.0449 \\
\hline 11 & 23571.347 & 190108.281 & 23570.890 & 190107.264 & 0.455 & 1.017 & 0.2070 & 1.0343 \\
\hline 12 & 23761.791 & 190129.255 & 23760.610 & 190129.468 & 1.181 & -0.213 & 1.3948 & 0.0454 \\
\hline 13 & 23806.329 & 190114.532 & 23813.030 & 190112.546 & -6.702 & 1.986 & 44.9168 & 3.9442 \\
\hline 14 & 23321.07 & 190028.599 & 23322.240 & 190031.811 & -1.170 & -3.212 & 1.3689 & 10.3169 \\
\hline 15 & 23874.667 & 190884.311 & 23873.070 & 190882.803 & 1.596 & 1.508 & 2.5472 & 2.2741 \\
\hline 16 & 23914.205 & 190515.711 & 23912.760 & 190513.713 & 1.445 & 1.998 & 2.0880 & 3.9920 \\
\hline 17 & 23981.299 & 190976.499 & 23978.990 & 190971.437 & 2.308 & 5.062 & 5.3269 & 25.6238 \\
\hline 18 & 23553.895 & 190759.318 & 23555.95 & 190759.331 & -2.054 & -0.013 & 4.2189 & 0.0002 \\
\hline 19 & 23161.723 & 190071.223 & 23159.59 & 190070.232 & 2.134 & 0.991 & 4.5540 & 0.9821 \\
\hline & & & & & & & 163.3690 & 92.97245 \\
\hline & & & & & & RMSE & 3.0126 & 2.2727 \\
\hline
\end{tabular}




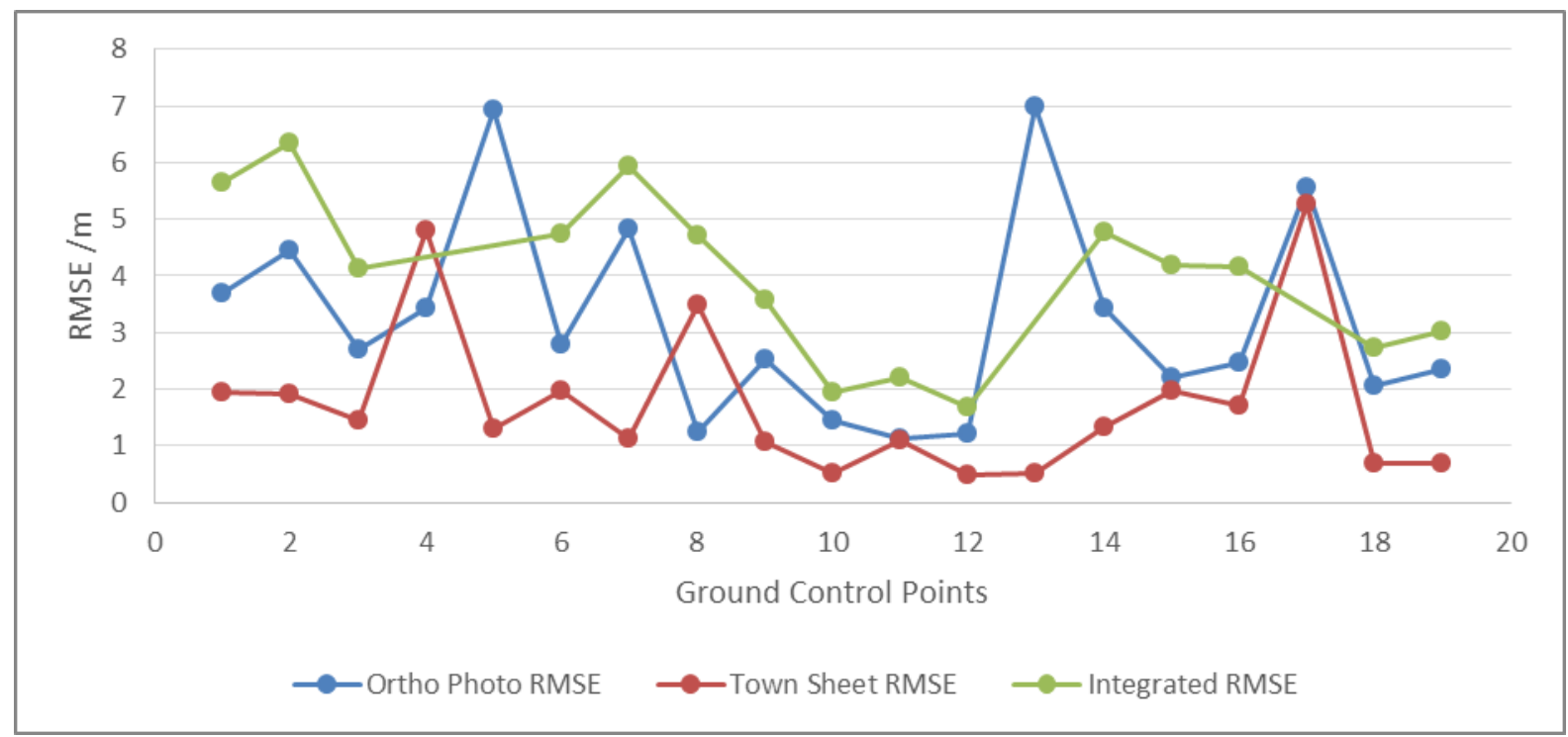

Fig. 5 RMSE of Integrated Dataset

\subsubsection{Uncertainties in the Orthophoto}

From Fig. 3, the discrepancies of the coordinates of the controls extracted from the orthophoto relative to the GPS data generally show an average deviation of about $2.79 \mathrm{~m}$ i.e. close to $3 \mathrm{~m}$. The use of orthophotos is mostly preferred by lots of disciplines since it has both pictorial information and planimetric correctness of ground features. However, some inherent errors in the dataset such as gaps due to cloud cover and limitation of the orthophoto rectification processing software could be responsible for the errors detected.

From Fig. 4, though the integrated data visually seem to match well with the GCP points of the Town Sheet and the orthophoto, Fig. 5 reveal the extent of positional errors in the dataset. These errors, which emanate from the individual data, have a cumulative effect on the overall position accuracy determined.

\section{Conclusions and Recommendation}

The Town Sheet used was found to have a better positional accuracy with RMSE of $1.2 \mathrm{~m}$ followed by the orthophoto with RMSE of $2.79 \mathrm{~m}$. The scale at which original data are produced to a large extent determines the level of accuracy of the data. Integrated dataset bear the cumulative inherent errors of the original data. The techniques adopted in carrying out GPS observations and processing increase the reliability of the results obtained.

It is recommended that dependency on spatial dataset to support decision-making should be encouraged; however, such dataset should be subjected to rigorous positional assessment to enhance the reliability of such decisions.

\section{Acknowledgements}

The authors are grateful to the Survey and Mapping Division of the Lands Commission, Takoradi, Ghana and the Geomatic Engineering Department of UMaT, Tarkwa for providing resources for the study.

\section{References}

Anon. (1998), "Federal Geographic Data Committee, Subcommittee for Base Cartographic Data: Geospatial Positioning Accuracy Standards - Part 3: National Standard for Spatial Data Accuracy', (FGDC-STD-007.31998), pp. 4-18.

Anon. (2006), "Sekondi-Takoradi Metropolitan Assembly", www.stma.ghanadistricts.gov.gh, Accessed: February 12, 2014

Becek, K.., Ibrahim, K.., and Barussalam, B., (2011), "On the Positional Accuracy of the Google Earth Imagery", Proceedings of FIG Working Week on Bridging the Gap between Cultures, Marrakech, Morocco, 8 pp.

Boak, E. H. and Turner, I. L. (2005), "Shoreline definition and detection: a review", Journal of Coastal Research, Vol. 21, No. 4, pp. $688-703$.

Congalton, R. G. and Green, K. (2008), “Assessing the accuracy of remotely sensed data: principles and practices", CRC press, pp.19-53.

Dolan, R., Fenster, M. S. and Holme, S. J. (1991), "Temporal Analysis of Shoreline Recession and Accretion", Journal of Coastal Research, Vol. 7, No.3, pp. $723-744$. 
Erwig, M., Gu, R. H., Schneider, M. and Vazirgiannis, M. (1999), "Spatio-temporal data types: An Approach to Modeling and Querying Moving Objects in Databases", GeoInformatica, Vol. 3, No. 3, pp. 269 - 296.

Farah, A. and Algarni, D. (2014), "Positional Accuracy Assessment of Google Earth in Riyadh", Artificial Satellites, Vol. 49, No. 2, pp. 101-106.

Foster, E. R. and Savage, R. J. (1989), "Methods of Historical Shoreline Analysis", Coastal Zone '89, American Society of Civil Engineers, Vol. 5, pp. $4434-4448$.

Galgano, F. A. and Douglas, B. C. (2000), "Shoreline Position Prediction: Methods and Errors", Environmental Geosciences, Vol. 7, No. 1, pp. $23-31$.

Girres, J. F. and Touya, G. (2010), "Quality Assessment of the French Open Street Map Dataset" Transactions in GIS, Vol. 14, No. 4, pp. $435-459$.

Kumar, T. S., Mahendra, R. S., Nayak, S., Radhakrishnan, K. and Sahu, K. C. (2010), "Coastal Vulnerability Assessment for Orissa State, East Coast of India", Journal of Coastal Research, Vol. 26, No. 3, pp. 523 - 534.

Naji, P., Alsufyani, N. A. and Lagravère, M. O. (2013), "Reliability of Anatomic Structures as Landmarks in Three-dimensional Cephalometric Analysis using CBCT", The Angle Orthodontist, Vol. 84, Vol. 5, pp. $762-772$.

Paredes-Hernández, C. U., Salinas-Castillo, W. E., Guevara-Cortina, F., and Martínez-Becerra X. (2013), "Horizontal Positional Accuracy of Google Earth's Imagery over Rural Areas: A Study Case In Tamaulipas, Mexico", Boletim de Ciências Geodésicas, Vol.19, No.4, pp. 588601.

Potere, D. (2008), "Horizontal Positional Accuracy of Google Earth's High-resolution Imagery Archive", Sensors, Vol.8, No. 12, pp. 7973 7981.

Pujotomo, M. S. and Sudibyakto, H. A., (2009), "Coastal Changes Assessment using Multi Spatio-Temporal Data for Coastal Spatial Planning Parangtritis Beach Yogyakarta Indonesia", Doctoral Dissertation, Universitas Gadjah Mada, Yogyakarta, 112 pp.

Srivastava, A., Niu, X., Di, K. and Li, R. (2005), "Shoreline Modeling and Erosion Prediction", Proceedings of the ASPRS Annual Conference, Baltimore, Maryland, pp. 7 - 11.

Thieler, E. R., O'Connell, J. F. and Schupp, C. A. (2001), "The Massachusetts Shoreline Change Project: 1800 s to 1994”, Technical Report, USGS Administrative Report NOAA, Boston, $26 \mathrm{pp}$.

Yousefzadeh, M. and Mojaradi, B. (2012), "Combined Rigorous-Generic Direct Orthorectification Procedure for IRS-P6 Sensors", ISPRS Journal of Photogrammetry and Remote Sensing, Vol. 74, pp. 122 - 132.

Zhang, K., Douglas, B. C. and Leatherman, S. P. (2004), "Global Warming and Coastal Erosion", Climatic Change, Vol. 64, No. 1-2, pp. $41-58$.

Authors

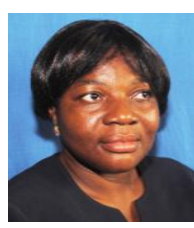

Dr Mrs C. B. Boye is a senior lecturer at the Geomatic Engineering Department, University of Mines and Technology, Tarkwa, Ghana. She holds BSc degree in Geodetic Engineering from Kwame Nkrumah University of Science and Technology, Kumasi, a professional Master degree in Geo-informatics from (ITC), Enschede, and $\mathrm{PhD}$ degree in oceanography from the University of Ghana, Legon. She is currently involved in shoreline change modelling and prediction, geographic information management and engineering surveying.

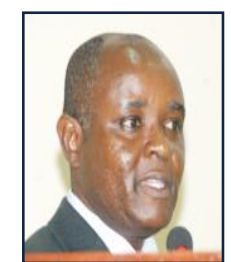

Dr K. Appeaning Addo is a senior lecturer at the Department of Marine and Fisheries Sciences at the University of Ghana, Legon. He holds BSc and MPhil degrees in Geodetic Engineering from Kwame Nkrumah University of Science and Technology, Kumasi, and has a $\mathrm{PhD}$ degree in Geomatic Engineering from University of Newcastle, UK. He is a coastal processing analyst and lectures in Coastal Geomorphology, Physical Oceanography and Coastal Processes. He offers Consultancy services in coastal processes, shoreline change modelling and predictions, and climate change.

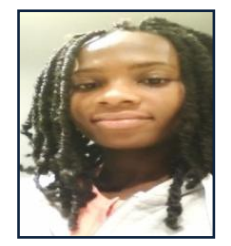

Miss E. A. Williams, holds BSc degree in Geomatic Engineering from the University of Mines and technology, Tarkwa. She is currently a national service person with the Department where she assists lecturers and students perform academic and practical tasks. Her research interest is in Geospatial mapping sciences and monitoring. She loves reading. 